\title{
Strenght analysis chassis of UM electric cars using finite element method
}

\author{
Mardji $^{1}$, Andoko $^{1}$, and Dani Prasetiyo ${ }^{1}$ \\ ${ }^{1}$ Department of Mechanical Engineering, State University of Malang, 65145 Malang, Indonesia.
}

\begin{abstract}
Chassis on the vehicle serves as the main weight support vehicle. Designing a precise chassis will give optimal results between the safety level and the size of the construction, so that finite element simulation analysis is required to know how strong the chassis sustains the load on it. The purpose of this research is to get the result of chassis simulation on UM electric car when getting the loading by using ANSYS 18.1 software. As for the step this study started from chassis modeling using Autodesk Inventor Professional 2018 software and finite element simulation using static structural feature in software ANSYS 18.1. From the simulation result obtained Equivalent Stress 59,983MPa, Equivalent Elastic Strain 33,25x10-5 mm / mm Total Deformation 2,43mm and safety factor 3,55 .
\end{abstract}

\section{Introduction}

The chassis of the vehicle serves as a body support and consists of chassis, engine, power transfer system, wheels, steering system, suspension system, brake system, passenger and other fittings [1]. Properly designing a chassis will provide optimal results between the safety level and the construction size [2], so it takes finite element simulation analysis to find out how strong the chassis sustains the load on it.

The chassis should be strongly designed because it has an important role to avoid fatal accidents. With the development of increasingly sophisticated technology, design problems and simulation analysis can be done easily before a project is made. Thus a component can be evaluated before it is produced and applied.

In engineering, the calculation of the axial internal forces on the chassis of space can be done in various ways. One way to calculate the internal force of the axial chassis space is by using the finite element method. The finite element method is a modeling method of an object dividing in a small part which as a whole still has the same properties as the whole before dividing into a small (discretized) section [3].

Based on the above problems, the researcher performs simulation to get chassis power analysis result on UM electric car prior to manufacturing when getting the loading from above by using ANSYS Workbench 18.1 software.

\footnotetext{
* Corresponding author: mardji.ft@um.ac.id
} 


\section{Literature review}

\subsection{Chassis}

Chassis serves as a heavy support of vehicles, engines and passengers. Usually the chassis is made of steel frame that holds the body and engine of a vehicle. When the vehicle body manufacturing process is formed in accordance with the chassis structure. Car chassis is usually made of metal or composite. The material must have the power to support the load from the vehicle. Chassis also serves to keep the car rigid, stiff and not bending [4]. Figure 1 shows a modeled chassis that have designed using Autodesk Inventor Professional 2018 software.
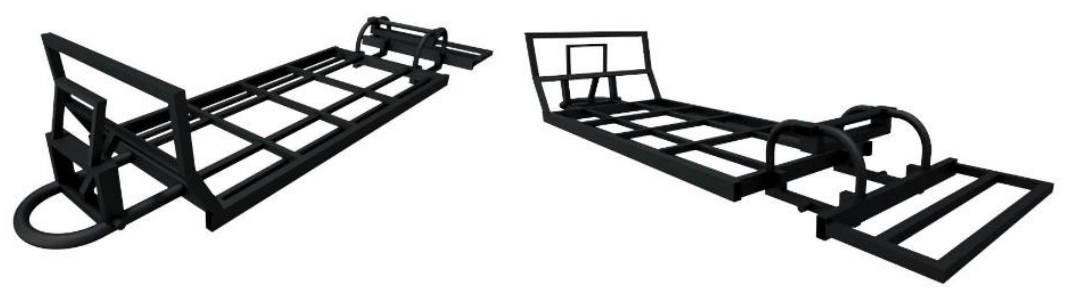

Fig. 1. Design of UM electric car chassis using Autodesk Inventor Pro 2018.

\subsection{Finite element}

The finite element method is a numerical method used to solve engineering problems and mathematical problems of a physical phenomenon. Types of technical and mathematical physical problems that can be solved by elemental methods such as stress / stress analysis, Buckling and Vibration Analysis [5].

\section{Method}

Finite element analysis (FEA) is performed on every construction to investigate the stress, strain, deformation, and safety factor. This type of analysis provides a means for conducting easy and efficient research on various parameters used with easily evaluable design and manufacturing conditions.

\subsection{Construction Model}

The table below shows the specifications of the material used to make UM electric car chassis using steel structure material.

Table 1. Material properties.

\begin{tabular}{|c|c|}
\hline Properties & Baja Struktur \\
\hline Density & $7.85 \mathrm{~g} \mathrm{~cm}^{\wedge}-3$ \\
\hline Poisson's Ratio & 0.3 \\
\hline Tensile Yield Strength & 250 \\
\hline
\end{tabular}




\subsection{Simulation}

The designed chassis is then analyzed using ANSYS Workbench 18.1 for stress, deformation, and security factors. This process generates a mesh with 104759 nodes and 52012 elements. In this simulation, the chassis is assigned a force at certain points according to the load to be assigned with a total of $7750 \mathrm{~N}$ styles. The geometry of the chassis at Figure 2 is adapted to the material chosen, ie the steel structure.

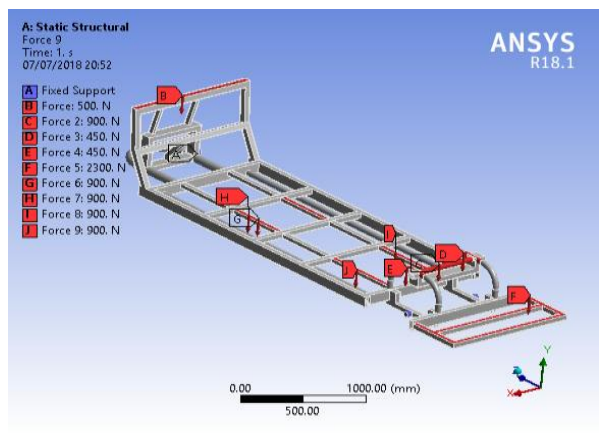

(a)

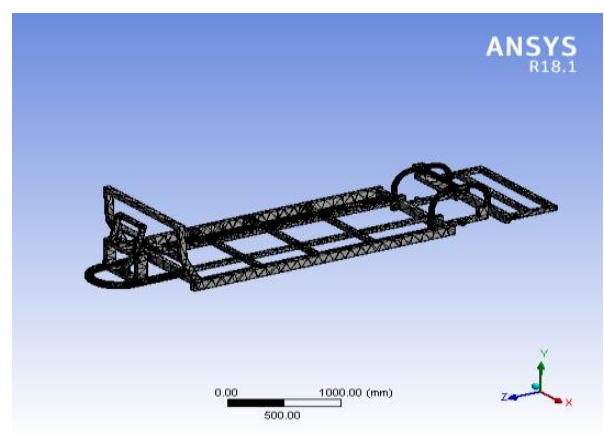

(b)

Fig. 2. Static structural analysis result (a) and meshing result (b).

\section{Result and Disscusion}

\subsection{Equivalent (von-mises) stress}

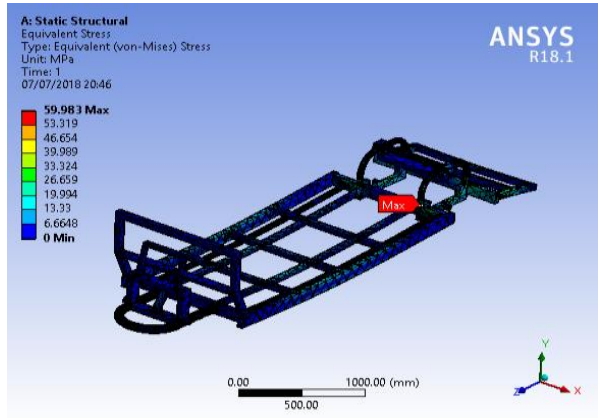

(a)

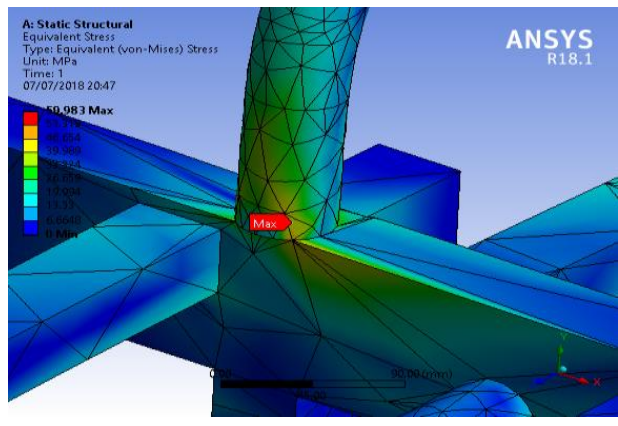

b)

Fig. 3. Maximum equivalent stress of chassis electric car UM.

The simulation results show that the maximum equivalent stress is on the red mark that is equal to $59,983 \mathrm{MPa}$, and minimum equivalent stress $0 \mathrm{Mpa}$ is on the blue colored part. 


\subsection{Equivalent Elastic Strain}

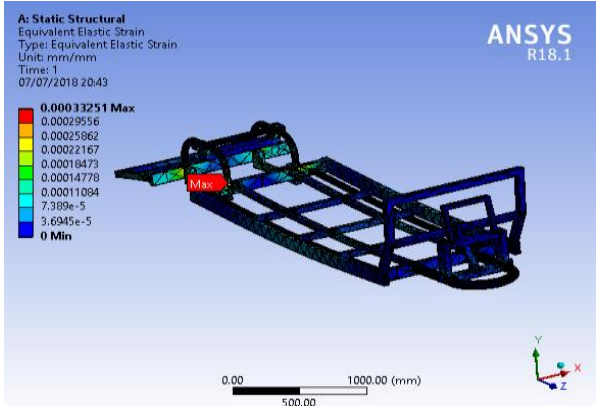

(a)

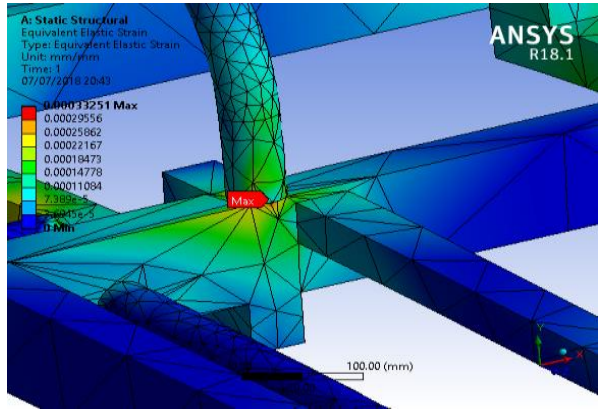

(b)

Fig. 4. Maximum equivalent elastic strain of electric car UM.

Figure 4 shows the simulation results that the maximum equivalent elastic strain is at the red mark of $33.25 \times 10-5 \mathrm{~mm} / \mathrm{mm}$, and the minimum equivalent elastic strain of $0 \mathrm{~mm} / \mathrm{mm}$ is in the blue portion.

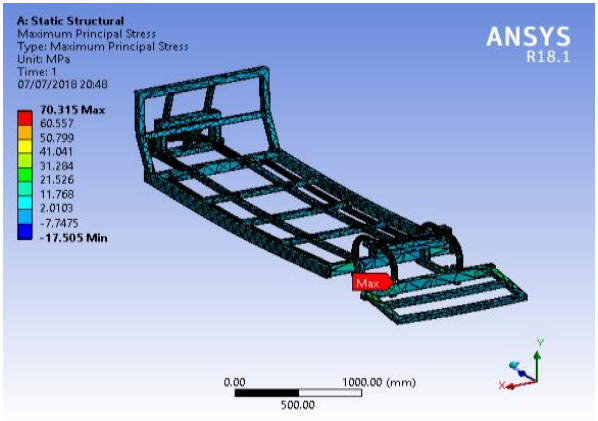

(a)

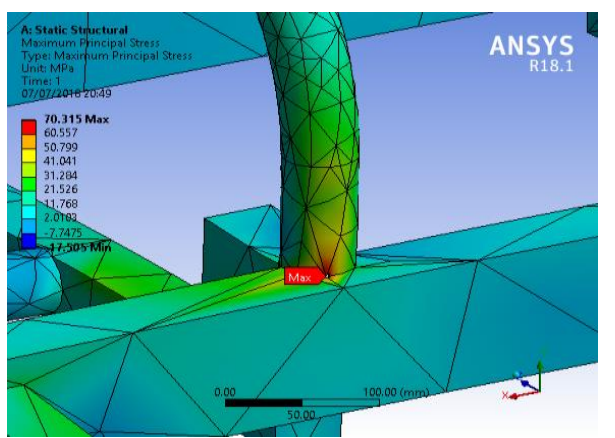

4.3 Maximum Principal Stress

Fig. 5. Maximum principal stress of chassis electric car UM.

Figure 5 shows the simulation result that the maximum principal stress is on the red mark which is $70,315 \mathrm{MPa}$, and the minimum principal stress $-17,505 \mathrm{MPa}$ is on the blue colored part. 


\subsection{Total Deformation}

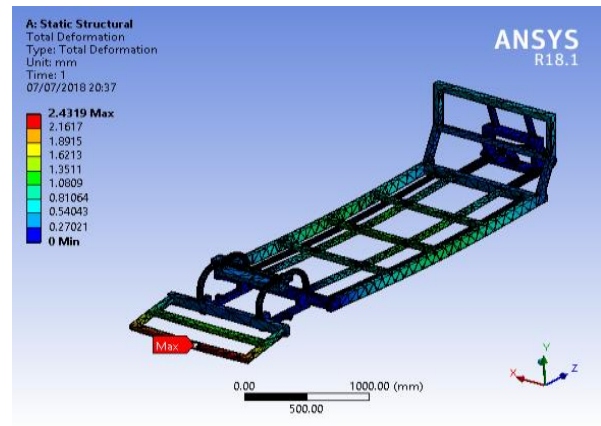

(a)

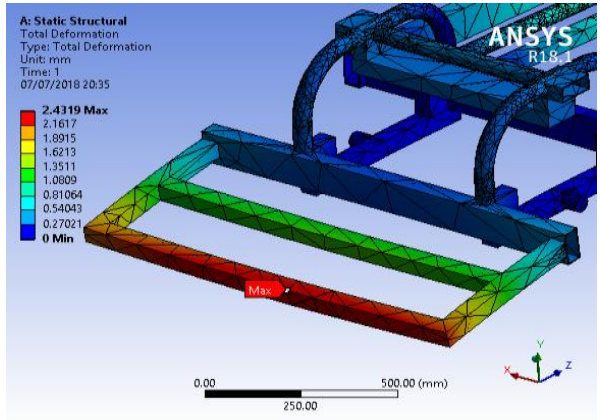

(b)

Fig. 6. Total Deformation of chassis electric car UM

The simulation results at Figure 6 show that the total deformation is in the place where the battery is located at $2.4319 \mathrm{~mm}$, and the minimum total deformation $0 \mathrm{~mm}$ is on the blue colored part.

\subsection{Safety Factor}

The safety factor is calculated by reference to the quotient of the yield strength divided by the magnitude of the voltage occurring.

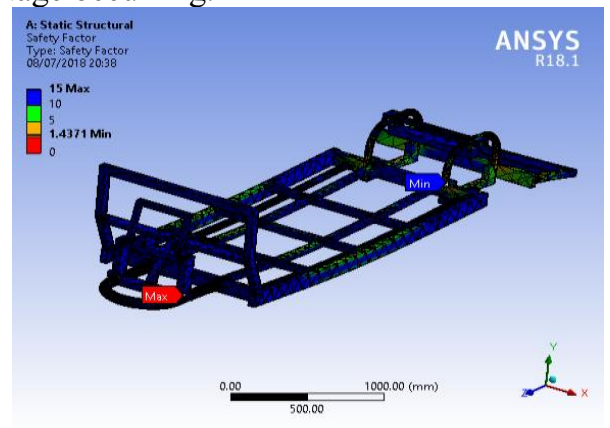

Fig. 7. Safety factor of chassis electric car UM.

It shows at Figure 7 that the minimum security score obtained from the analysis is 1.4371 , therefore it can be stated that the framework of the electric car is above the safe limit of the material.

\section{Conclusions}

From the calculation and simulation using Ansys Workbench 18.1 software, obtained the conclusion of chassis analysis with steel material structure as follows: 
Table 2. Conclusions.

\begin{tabular}{|l|c|c|}
\hline Information & Max & Min \\
\hline Equivalent (von-mises) stress & $59,983 \mathrm{MPa}$ & 0 \\
\hline Equivalent elastic strain & $33,25 \times 10^{-5} \mathrm{~mm} / \mathrm{mm}$ & 0 \\
\hline Maximum principal stress & $70,315 \mathrm{MPa}$ & $-17,505 \mathrm{MPa}$ \\
\hline Total Deformation & $2,4319 \mathrm{~mm}$ & 0 \\
\hline Safety Factor & 15 & 1,4371 \\
\hline
\end{tabular}

The authors acknowledge to State University of Malang for Hibah Penelitian PNBP UM 2018 with contract number 2.3.144/UN32.14/LT/2018.

\section{References}

1. Novian, s. m., et al., Biltek Journal, 4 (2016)

2. Setyono, B., Et Al., Journal Of Applied Science And Technology III, (2015)

3. Widyawati, O., Et Al., Jrsdd Journalm, 4 (2016)

4. Fadila, A. \& Sham, B., Dynamic E-Journals, 6 (2013)

5. Marshall, H., Stress Analysis on Frame of Sinosi Electric Cars using Finite Element Method. Thesis. University Of Jember. (2013) 